\title{
Histeri ve Obsesyon Nevrozunda Cinsiyetlenme Üzerine
}

\author{
Neli Gagua Sinem Baltac1 \\ Orta Doğu Teknik Üniversitesi
}

Öz

Histeri terimi eski dönemlerden beri kadın ile obsesyon terimi ise erkek ile ilişkili kullanılmıştır. Freud ve Lacan'ın söylemlerinde de bu yapılanmaların cinsiyetlenme ile eşleştirilerek kullanıldığı görülmektedir. Ancak Lacan'ın belirli bir cinsiyetin belirli yapılarla sınırlı olmadığını vurguladığı yazıları da bulunur. Güncel çalışmalarda da kadın obsesyonu ile ilgili tartışmalar sunulmuştur. Bu yazıda, öznenin kurulumunda histeri ve obsesyon nevrozundaki farklılaşmanın temelleri ve bu farklılıkta cinsiyetlenme konuları incelenmiştir. Ayrıca kadın obsesif yapılanma ile ilgili olası tartışmalara yer verilmiş ve konu kültür ve söylem bağlamında değerlendirilmiştir. Buna göre, Lacan histeri ve obsesif yapılanmalarının öznenin kurulum aşamasında Başka'nın arzusu ile ilişkilenmesi üzerinden farklılaştı̆ı̆ı belirtir ve Freud'un bu ayrımı biyoloji ile ilişkilendirmesinin ötesine geçer. Ona göre, biyoloji/gerçek ancak dildeki/simgeseldeki anlamıyla değerlendirilebilirdir. Fallusun metaforik olarak ele alınmasıyla, biyolojik olarak kadın veya erkekten değil, konum olarak dişillik veya erillikten bahsetmeye geçilir. Yapılanmalar da cinsiyetlenmedeki konumlanmayla aynı biçimdedir. Ancak fallusun değerini Başka'nın söyleminden alması, konumlanmada değişimin söz konusu olabileceğine dair işaret olarak görülebilir. Arnavutluk’taki kadın ve erkek konumlanmalarının değişebildiği yeminli bakireler geleneği, cinsiyetlenmenin söylem içinde kurulan bir konumlanma olduğuna örnek oluşturmaktadır.

Anahtar Sözcükler: cinsiyetlenme, konum, özne, kültür, obsesyon, histeri. 


\title{
Sexuation in Histeria and Obsessional Neurosis
}

\author{
Neli Gagua Sinem Baltac1 \\ Middle East Technical University
}

\begin{abstract}
Since ancient times, hysteria is associated with women whereas obsession is related to men. Both in Freud's and Lacan's works, these structures are associated with sexuation processes. Nevertheless, in Lacan's certain works, it is emphasized that a subject's structure is not limited to biological sex. There are discussions about obsessive women in contemporary studies. In this study, alongside process of sexuation, fundamentals of subject's structural differentiation in hysteria and obsession are discussed. Moreover, discussions about obsessive structuring of women and roles of culture or discourse are observed. Accordingly, Lacan emphasizes that hysterical and obsessive structuring is a product of a subject's relation to the Other's desire; thus, Lacan moves beyond Freud who has associated structuring with biological sex. Lacan articulates that real/biology can only be conceivable through its meaning in symbolic/language. With such conceptualization, phallus is regarded as metaphorical and instead being biologically men or women, it is positioning of subject that determines his/her femininity or masculinity. In this sense, process of subject's structuring is parallel to sexuation. Since it is the Other's discourse that determines value of phallus, positions in regard to sexuation is subject to change as well. This phenomenon is exemplified by an Albanian tradition known as "sworn virgins" in which positioning of men and women shift depending on discourse.
\end{abstract}

Keywords: sexuation, positioning, subject, culture, obsession, hysteria. 


\section{Histeri ve Obsesyon Nevrozunda Cinsiyetlenme Üzerine}

Psikotik ve pervert yapı ihtimalleri elendikten sonra nevroz yapısındaki kadın öznenin çoğunlukla histeri, erkek öznenin ise obsesif yapılanma içerisinde olduklarından söz edilmektedir (Evans, 2006; Fink, 1997; Miller, 2005; Soler, 1996). Bu iki terimin eski dönemdeki kullanımları da benzer bir atfa işaret eder. Histeri, Antik Yunanca'da rahim anlamına gelen hysteron kelimesinden türemiştir. Sonraları ise rahmin vücut içerisinde dolaşması olarak tanımlanan bir kadın hastalığı (Evans, 2006) ve kimi zaman da kadın vücudu ile alakalı belirli sinirsel fizyolojik rahatsılık (Gray, 2016) için kullanılmıştır. Freud'un histeriyi psikolojik süreçlerin bir sonucu olarak ele almaya başlamasıyla histerinin psikolojik kökenlerinin vurgulanmasına geçilmiş olur. Obsesyonun eski kullanımlarına bakıldığında ise kökeninin Latince kuşatmak anlamındaki obsessiodan türemiş obsessionem kelimesinden geldiği görülmektedir (Online Etymology Dictionary, 2017). Yine Freud'un obsesyondan bahsederken erkek özne olan 'he' yi kullandığg yazıları bulunur.

Freud ile benzer olarak Lacan da nevrotik yapılanmalardan bahsederken sıkl1kla obsesyonu erkek, histeriyi kadın özne olarak vurgulamaktadır. Öyle ki, histeri konusundan obsesyona geçerken "Şimdi leydiyi bir kenara bırakıp eril obsesyon stratejisine bakalım" ifadesini kullanır (Lacan, 2006a, p. 378). Bu terimlerin sıkı biçimde cinsiyetlenmeler (sexuation) ile eşlenerek kullanılmalarına karşın, Lacan'ın ne kadının zorunlu olarak histerik ne de erkeğin zorunlu olarak obsesif bir yapılanmada kurulmadığını ve bu yapıların biyoloji ile ilgili olmadığını belirttiği yazıları da bulunmaktadır (Lacan, 2006b, p. 379). Sonraki birkaç çalışmada ise obsesif yapıdaki kadınlar ele alınmış ve erkek obsesyon nevrozundan farklılığı tartışılmıştır (Gherovici \& Webster, 2014; Miller, 2005; Soler, 2006; Strauss, 2014). Görüldüğü üzere eskiden beri kadın ve erkek ile eş biçimde kullanılan bu yapılanmaların kurulum ile ilgili farklılıkları nereden gelmektedir? Histeriyi kadın özne ve obsesyonu erkek özne ile eşleştiren Lacan'a göre bu farklılıkları oluşturan nedir? Sonraki çalışmalarda kadın obsesif ya da erkek histeri ile ilişkili çıkan tartışmalar bize ne sunmaktadır?

\section{Öznenin Kurulumu: Histeri ve Obsesyon Nevrozunun Farklılaşması}

Lacan başlangıçtan itibaren yaşayan oluşumun (living being) varoluşsal yapısını sonradan ortaya koyacak olan bir boşluğun, bir yarığın etrafında kendini bir ağ gibi ördüğünü belirtmektedir. Bu yarılma öznenin kendi varlığı ile Başka (the Other) arasında meydana gelen ve onun varlığını kuran şeyin kendisi olarak işlev görür (Fink, 1997). Bu ontolojik yapılanma biçimine bağlı olarak, özne üç temel yapıda kendini kurar: psikoz, perversiyon ve nevroz. Lacan nevrotik yapılanmadaki öznelerin Başka'nın $\operatorname{arzusu}^{1}$ ile kurduğu ilişkilenme biçimlerine göre üç alt yapıya daha ayrıldı̆̆ını belirtir (Fink,

\footnotetext{
${ }^{1}$ Lacan, ihtiyaç, talep ve arzu (need-demand-desire) olarak özne'nin kurulumunu belirleyen temel konular
} 
1997). Histeri ve obsesyon da bu nevrotik yapılanma içindeki altyapılar olarak yer almaktadır.

Özne, kişinin bedeni ile Başka arasındaki etkileşimin sonucu olarak ortaya çıkmakta/kurulmaktadır (Verhaeghe, 2008). Buna göre, yaşayan oluşumun yemek, içmek gibi ihtiyaçları (need) Başka tarafından karşılanır (Evans, 2006). Ancak bir süre sonra ihtiyaçların karşılanmasının bedensel gereksinimlerin yanı sıra Başka'nın sevgisinin işareti olmaya başlamasıyla beraber talep (demand) başka bir anlam kazanır (Evans, 2006). Buna göre, bedensel ihtiyaçlar karşılanabilir olsa da yanında getirdiği sevgi görme bileşeni baki kalır ve bu artakalan unsur arzuyu (desire) oluşturur. Nevrotik öznenin yapılanması, kendisiyle Başka arasındaki etkileşimden oluşan bu arzu ile bağlantılıdır (Verhaeghe, 2008). Arzu, öznenin ihtiyaçları giderildiğinde dahi aradığı, arta kalan bir şeye işaret eder, ihtiyacın ötesinde Başka ile arasındaki bir ilişkilenme kurar (Verhaeghe, 2008). Bu talepleri beden ile ilişkili olarak okuyan Başka'nın tepkisi onun kendi arzusunu içerecektir. Özne, kendi bedenini işte Başka'nın tepkilerinde okuduğu bu arzuya göre anlamlandırmaya ve kendi varoluşsal eksiğini kapatmaya çalışır (Verhaeghe, 2008). Özne, kendisini bu arzuya göre konumlandırır. Bu noktada öznenin ve Başka'nın arzusunun arasındaki sınır muğlaklaşacaktır. Lacan'ın “Öznenin arzusu, Başka’nın arzusudur” sözü ile kastettiği özne ve Başka arasındaki dinamikle oluşan bu arzudur (Verhaeghe, 2008).

Bu bağlamda çocuk, annesinin kendisinden ne beklediğini anlamlandırmaya çalışır; fakat annesi bunu dile getiremez çünkü kendisi de bilmez (Fink, 1997). Annesinin davranışları ve konuşması arasındaki çelişkiyi fark eden çocuk, annesine karşı yöneltilmiş bilinçdışı "ne istiyor" sorusuna temel düşleminde (fantasm) yanıt bulur. İki yapının kökeni, kişinin temel düşleminde, yani öznenin Başka'nın arzusuyla ilişkilenme biçiminde yatar (Miller, 2005). Bir başka deyişle özne, kendi varoluşunun ve içerisine girdiği dil sistemindeki gösteren ${ }^{2}$ in birleşmesindeki imkansılıl̆ğ verdiğ anlam çerçevesinde yapılanır (Strauss, 2014). Buna göre, kişinin bedensel varoluşu asla dildeki bir gösteren ile gösterilemez ve özne temel düşleminin çerçevesinde bu imkansızlıkla baş etmeye çalışır. Dolayısıyla nevroz, gösteren karşısında öznenin sorduğu varoluş sorusudur (Lacan, 2006). Bu bağlamda temel düşlem, öznenin yapılanmasının esasında yatan temsil olup arzu etrafında şekillenen özne ve Başka'nın ilişkisini yapılandırmaktadır. Bu temel düşleminin oluşma biçimi, obsesyon ve histeri konumlanmasında kilit rol oynamaktadır (Verhaeghe, 2008). Her özne, temel düşlem çerçevesinde beden, jouissance ${ }^{3}$, otorite ve bilgi ile ilişkilenmelerinde farklı farklı konumlanır. İlk başta Başka ile ilişkilenme sonucunda oluşan bu temel düşlem, öznenin diğer insanlarla kuracağı

bulunduğunu belirtir. Buna göre, nevrotik yapılanma ihtiyaç ve talebin de ötesinde olan arzu üzerine bir konudur. Nevrotik yapılanma, Başka'nın arzusu ile ilişkilenme biçimlerine göre üç farklı alt yapıya ayrılmaktadır.

${ }^{2}$ Saussure'den gösteren kavramını alıp geliştiren Lacan, dilin gösterenler zinciri olduğunu söyler. Buna göre gösteren, özneyi bir başka gösteren için temsil eder.

${ }^{3}$ Jouissance, Lacan'ın dış dünyadan uzaklaşmış, acı veren zevk için kullandığı terimdir. 
ilişkiye de sonrasında yansımaktadır (Fink, 2016).

Yukarıda belirtildiği gibi öznenin temel düşlemi, Başka ile olan etkileşimin ürünüdür (Verhaeghe, 2008). Histerik yapılanmanın içerisinde Başka'nın verdiği veya öznenin aldığı mesaj, kendisinin yetersizliği ve Başka'nın arzusunu tatmin etmediği yönündedir (Verhaeghe, 2008). Bu bağlamda histerik özne, annenin dilinde onun (Başka'nın) arzusunun baba tarafından da tam olarak doyurulmadığını sezer ve Başka'nın arzusuna dair bilgiyi başka birilerinde aramak üzere hareket eder; ama onи asla bulamayacağı bir arayıştır bu. Arzusunu efendide arayan histerik özne, arzusuna dair bilgiyi devamlı olarak karşısındaki bilirkişi konumuna koyduğu kişiden talep eder; ama alacağı bilgileri de reddedecektir (Verhaeghe, 2008) ki böylece temel düşlemi Başka’nın arzusunu sürdürmek olan histerik öznenin arzusu devam edecektir.

Histeri yapılanması tatminsizliğin artakalanı ile bağlaşırken, obsesif yapılanma tam tersine travmatik olan zevk fazlası ile ilişkilendirilmektedir (Verhaeghe, 2008). Obsesif özne, Başka'nın mesajını, eğer kendisi yeterince çaba sarf ederse onun arzusunu tatmin edebileceği yönünde yorumlar. Bunun yanı sıra obsesif özne, annesinin söylemindeki babanın Başka’nın arzusunu kısmen doyurabildiğini sezer ve o kalan eksiği kendisinin doldurabileceğini varsayar (Dor, 1999). Dolayısıyla obsesif özne, babanın otoritesini tanımakla beraber kendisini ona rakip olarak da görebilmektedir (Verhaeghe, 2008). Bu bağlamda obsesif yapılanmada temel düşlem Başka'nın tüm arzusunu tatmin etmek; dolayısıyla onu yok saymak veya öldürmektir (Dor, 1999). Bu iki yapılanma, anksiyeteyi deneyimleme biçimleriyle de farklılaşmaktadırlar (Verhaeghe, 2008). Anksiyete, histerik özne için Başka’nın arzusunu tatmin etmeyecek olmakla alakalı iken; obsesif özne için Başka'nın arzusunu fazla tatmin edip yok olmak ile ilişkilidir.

Farklı bastırma biçimleri ile sonuçlanan bu iki nevroz seçimi, klinik tabloda da bastırılanın geri dönüşü, yani semptom olarak ortaya koyulmaktadır (Soler, 1996). Bu semptomatik konumlanmaya göre histeri ve obsesyonun farklılıkları ortaya çıkar. Histeride bastırlan bedende geri dönerken, obsesyon nevrozunda basttrllan zihinde geri dönmektedir (Fink, 1997). Bu bağlamda, obsesyon nevrozu jouissance'a yönelik güçlü bir çekim, histeri ise jouissance'a karşı olan tiksinme anlamına gelmektedir. Başka ifadeyle histerik yapılanma pasif bir konum olup kişinin cinselliğe karşı temel tiksintisine; obsesyon nevrozu ise aktif bir konum olup ilkel cinsellik karşısında çok fazla zevke işaret etmektedir (Soler, 1996). Bastırma biçimlerindeki farkll1ıklarla ortaya konan bu iki nevrotik konum, aynı zamanda çoğunlukla deneyimledikleri duygularla da ayrışrlar. Jouissance’’ deneyimleme biçimlerinin sonucu olarak, obsesyon nevrozunda çoğunlukla kişinin kendisine yönelik suçluluktan; histeride ise karşıdakini suçlama tavrından bahsedilmektedir (Atmaca, 2017; Soler, 1996).

Klinik tablodaki görünen/semptomatik farklılıklar önemli olsa da Lacan, Freud'un bilinçdışı işleyişini ele alıp geliştirirken semptom veya jouissance'ın kendisiyle değil, öznenin dilindeki haline 
odaklanır (Soler, 1996); çünkü Lacan'a göre bu yapıların oluşumu dilde meydana gelir. Buna göre özne, dil sonucunda oluşur ve gösteren zincirinde varoluş sorusunu cevaplamak üzere arzular (Soler, 1996). Bu arzulama süreci temel eksikliği ortadan kaldırmamakla beraber birgün eksikliğin ortadan kalkabileceği düşlemi ile işler. Bu bağlamda nevrotiğin sorusu “Ben oluş olarak neyim?” sorusudur. Obsesyon nevrozunda temel soru "Ben yaşayan bir oluş olarak neyim?” iken histerik yapıda "Ben cinsel bir oluş olarak neyim?" sorusudur. Obsesyon nevrozu ile histerinin temelde bu soru ile ayrıldığı belirtilebilir (Evans, 2006). Histeriğin temel sorusu cinsellikle ilgili iken; obsesif özne bu soruyu geri çevirmeye ve hararetle kendi oluşunu kanıtlamaya çalışır. Bu kanıtlama çabası obsesyon nevrozunda histeriye kıyasla daha fazla anksiyetenin olmasının da sebebidir: Obsesif kişi varoluşunu kanıtlayacağı eksiksiz bir dünya yaratma çabasında olup bu düşlemine yaklaştı̆̆ zaman anksiyete deneyimler ve bu şekilde arzusunu sürdürmesi mümkün olur (Lacan, 2004). Histeri nevrozunda özne temel düşlemi ve sorusu çerçevesinde Başka tarafindan arzulanmayı arzular; obsesyon nevrozunda ise öznenin Başka ile olan bă̆ı reddedilir. Bu bağlamda histeriğin oluşu karşısındakinin kendisini arzulamasına bağlı iken obsesif arzulamayan, eksik olmayan yani ölü olan Başka’yı düşler (Gherovici \& Webster, 2014). Feminen bir soru yönelterek karşısında arzulayan bir baba görmek isteyen histeriğe karşın; obsesif arzulamayacak kadar eksiksiz bir baba ister (Strauss, 2014). Bu bağlamda obsesyon nevrozu kastrasyonu ${ }^{4}$ hem yüceltir hem de kastrasyonun üstünü örter (Miller, 2005). Temel düşlemi Başka tarafindan arzulanmak olan histeriğin ve temel düşlemi arzulamayan Başka olan obsesifin bir sorun yaşadıklarında verdikleri tepkilerin farklılaşması da söz konusudur (Soler, 1996). Örneğin, histeriğin yaşadığı bir sorunu çevresindeki çoğu insanla paylaşıp kolektif hale getirmesi ve obsesifin de bir problem karşısında kendisini çevresinden uzaklaştırıp tek başına düşünerek çözmeye çalışması görülebilir (Soler, 1996).

\section{Histeri ve Obsesyon Nevrozunda Cinsiyetlenme}

Lacan tam bir Freudyen olmasına rağmen ondan ayrılan birçok nokta da belirtmiştir (Durudoğan, 2015). Freud için cinsel gelişim biyolojik olarak ve doğal nedenlerle açıklanmaktayken, Lacan için öznelliğin oluşumu dilin yapısında saklıdır ve psikoseksüel gelişim de öznenin dille olan ilişskisi dışında ele alınamaz. Freud'a göre, çocuğun biyolojik olarak erkek veya kız olması yani penise sahip olması ya da olmaması belirleyiciyken; Lacan için belirli bir organın önemi dil içerisinde anlaşılabilirdir. Bu bağlamda Lacan, penisin önemsiz olduğundan ama metaforik olarak fallusun temel gösteren olduğundan bahseder. Dolayısıyla Freud'u yeniden okuyan Lacan'a göre, gösteren olarak

${ }^{4}$ Freud'a göre kastrasyon kompleksi biyolojik bir temele sahip olup Ödipus kompleksinin sonuçlanmasıyla ilgilidir. Lacan'a göre ise kastrasyon, imajiner fallus'un sembolik eksikliğidir ve bu biyolojiye indirgenememektedir. Kastrasyonun kendisinin bir kompleks yaratmasından ziyade, kastrasyonun gerçekleşmemiş olmasının sorunsal teşkil ettiğini vurgulamaktadır. 
fallus, önemini Başka'nin söyleminden alır (Soler, 2006). Bu gösteren gücü, sevilmeyi ve tam olmayı temsil eder. Lacan'a göre bilinçdışı özne, cinsel ayrımını fallusa göre almakta olup; ya fallusa sahip olan ya da fallus olan konuma geçer (Homer, 2013). Fallusa göre gerçekleşen bu konumlanmalar kastrasyon, jouissance ve eksikliğin tanınması biçimleri ile beraber gerçekleşir. Fallusa sahip olma eril bir pozisyonken, fallus olma dişildir. Bu erillik veya dişillik konumları hem erkek hem de kadın için dil izin verdiği müddetçe ulaşılabilirdir (Homer, 2013). Bahsedilen konum bağlamlarından gidildiğinde Lacan, ne histeriğin zorunlu olarak kadın; ne de erkeğin zorunlu olarak obsesif yapıda olduğunu belirtmiştir (Lacan, 2006b). Burada önemli olan, histerik yapılanmadan bahsedilirken biyolojik ${ }^{5}$ olarak kadından değil bilinçdışı özne olarak kadından söz edilmesidir (Soler, 2006). Gösterenden yoksun olan kadın, biyolojik kadından ziyade kadınsı konumdur (Evans, 2006). Dolayısıyla, öznenin fallusla olan ilişkisi cinsiyetlenme konumların belirlemektedir (Evans, 2006).

\section{Kadın Obsesyon Nevrozu Üzerine Tartışmalar}

Lacan her ne kadar sıklıkla obsesyon için erkek, histeri için kadııı belirten şahıs zamirlerini kullansa da diğer yandan çalışmalarında cinsiyetlenmeyi biyolojik gelişimden öte, söylem ve Başka ile ilişkideki konumlar olarak ele almıştır. Günümüzde ise artan bir şekilde kadın obsesyon nevrozu ile karşılaşıldıı̆ından bahseden çalışmalar bulunmaktadır (Gherovici \& Webster, 2014). Bu çalı̧̧malarda kadın obsesyon nevrozunda, erkeklerde görülen semptomlara ek olarak kendilerine has semptomların varlığından söz edilmektedir (Gherovici \& Webster, 2014; Strauss, 2014). Bu farklılaşan belirtilerin doğurganlık, vücut kontrolü ve güzellik ile alakalı olabileceği ve semptomların ortaya çıkma şekillerinin de farklı olabileceği belirtilir (Strauss, 2014). Kadınların dişil bir vücuda sahip olmaları, kendilerinde anne ile (ilk Başka ile) daha çok ortak nokta olduğuna işaret etmektedir (Soler, 2006). Erkeklere kıyasla, vücutlarında eksikliği daha çok deneyimleyebildiklerinden, kadınların fallusa sahip oldukları düşlemine daha az kapılmış olmalarından bahsedilmektedir (Gherovici \& Webster, 2014). Dolayısıyla, kadın obsesyon nevrozunda fallus göstereni tarafindan aldatılmanın daha az yoğun olduğundan söz edilmektedir.

Fallusa sahip olma ile daha az büyülenmiş olmaları, obsesif kadınların kendi bilinçlerine daha az güvenmeleri anlamına gelmektedir; bu da kadınlarda bilişsel döngünün daha kolay kırılabildiğini göstermektedir (Gherovici \& Webster, 2014). Kadın obsesyon nevrozunda fallusa tam sahip olunmaması aynı zamanda ileride fallusa sahip olunabileceği imgesini kadınların erkeklerden daha çok yaşayabileceğini de ifade etmektedir. Yani fallusa sahip olabileceği ihtimali ile beraber gelen tüm

\footnotetext{
${ }^{5}$ Buradaki önemli olan nokta kadın ve erkek ile ifade edilenin biyolojik göndermede bulunmadığıdır: Gerçeğin ya da biyolojinin kendisi hiçbir zaman bir anlam taşımamaktadır (Homer, 2013). Gerçek, sadece sembolik alanda, yani dilde taşıdığı değer ile beraber anlam kazanabilir. Dolayısıyla, cinsiyetlenmeden bahsedildiğinde organın varlığından veya yokluğundan değil; bunun dildeki anlamından söz edilmektedir.
} 
güçlülük özlemi, kadın obsesyon nevrozunda daha belirleyici olabilmektedir. Dolayısıyla, fallusa tam anlamıyla sahip olmamanın ikircikli bir etkisi bulunmaktadır (Gherovici \& Webster, 2014).

Obsesyon nevrozundaki arzuyu reddetme hali, kadın obsesyon nevrozunda da belirleyicidir (Gherovici \& Webster, 2014). Tam da bu reddedilen arzu, ironik bir şekilde, kadın obsesyon nevrozunda dişillikle alakalıdır. Reddedilen arzu, feminen "zayıflık” yani zırhtaki yarık ya da imge yüzeyinde saklanan deliktir. Yani, kadın obsesyon nevrozunda dişilliğe saygı duyulmamakta, tam tersine küçümsenmektedir (Strauss, 2014).

Erteleme semptomu da hem erkek hem de kadın obsesyon nevrozunda belirgindir (Gherovici \& Webster, 2014). Kadınlardaki ertelemenin, fallusun birgün çıkacağı düşleminin uzantısı olarak "henüz hazır değilim daha sonra olacağım” gibi bir motivasyonla gerçekleştiğinden bahsedilmektedir. $\mathrm{Bu}$ bağlamda, erkek obsesyon nevrozundan farklı olarak kadınlarda "henüz fallusa sahip olmamak" şeklinde kendisini gösteren erteleme davranışının dişil bir ize sahip özgün bir fallik konuma işaret ettiği düşünülmektedir. Ayrıca erkek obsesyon nevrozu için literatürde anne tarafından yoğun bir libidinal yatırıma sahip özel çocuklar olduklarından bahsedilirken (Dor, 1999), kadın obsesyon nevrozu için favori çocuk olmadıkları ve ayrıcalığa sahip olmadıkları da ifade edilmektedir (Gherovici \& Webster, 2014).

Kadın obsesyon nevrozuna özgün bir başka kontrol alanının kadının bedenine ilişkin olduğu söylenmektedir (Gherovici \& Webster, 2014). Günümüzde kadının doğurganlığı ile ilgili birçok ifade bulunmaktadır: Aile planlaması, kadın doğum kontrol yöntemleri, regl düzensizliği ile ilgili tanımlar vb. Bu kavramlar, kadının bedeni üzerindeki kontrol etme, düzenleme ve beden üstünde hâkimiyet kurma olarak ele alınabilir. Bu bağlamda, arzunun kontrolünden, yani düzensiz olabilecek bir şeyin üstünü örtmekten bahsedilmektedir. Kadında doğurganlığın ertelenmesi, kadın vücuduyla karşılaşmanın geciktirilme çabası, obsesyon nevrozundaki kontrol etme düşlemiyle açıklanmaktadır (Gherovici \& Webster, 2014).

\section{Kültür ve Özne arasında, Konumlanma}

Strauss (2014) çalışmalarında kadınsı ve erkeksi konumlanmaların kadın ve erkeğin söylem içerisindeki gösterenlerinin değişimine bağlı olarak değiştiğini belirtir. Kültür olgusunu gösterenler sistemi olarak alan Levi-Strauss da evliliklerde kadının konumunu iki taraf arasındaki ilişkiyi kuvvetlendiren işleve sahip takas objesi olarak ele alarak bir gösterenin toplumdaki işlevi ile anlamlandırılabileceğini vurgulamaktadır (akt. Soler, 2006). Günümüzde artık kadının sadece ev ile erkeğinse sadece evin dışıyla alakalı rollerinin olmasına dair söylemlerin değişmesi farklı tür rolleri beraberinde getirmiştir. Yani, Başka'nın söyleminin netliğinin azalmasıyla beraber toplumsal cinsiyet rollerinde değişiklikler meydana gelmektedir. Bu bağlamda, değişen söyleme paralel olarak, kadının dişilliği ve erkeğin erilliği azalmakta denilebilir. 
Söylemin kadınsı ve erkeksi konumlanış üzerine etkisine bir başka örnek olarak Arnavutluk’ta yüzyıllardır devam eden 'yeminli bakire' geleneği verilebilir (Bilefsky, 2008; Lanchin, 2009).

Geleneğe göre, ailenin erkek reisi erkek bir vasi bırakamadığında, yani ailede erkek çocuk olmadığında, kız çocuklardan birisi erkeklere tanımlanmış vazifeleri yerine getirmek amacıyla erkek olarak konumlanır (Lanchin, 2009). Bu geleneğin yerine gelebilmesi için kız çocuklarının henüz bakireyken bakire kalacağına dair yemin etmesi ve akabinde de erkekler için tanımlanmış rolleri gerçekleştirmesi gerekir. Yeminli bakireler, erkek kıyafetleri giyer, silah taşır, sigara ve alkol kullanır, mahallesindeki kızlara 'yan bakanları' uyarır, mal alıp satarlar ve kadınlar için tanımlanmış ev işi gibi rolleri üstlenmezler. Yeminli bakireler, hayatları boyunca eril konumlanır ve çevresindekilerden de 'erkek' olarak muamele görürler. Bu gelenek değerlendirildiğinde, kadınların cinsiyetlerinin değil, sosyal konumlarının veya toplumsal cinsiyetlerinin değiştiği görülmektedir (Lanchin, 2009). Ek olarak, biyolojik olarak kadın olan öznenin toplumsal söylem içerisinde eril bir konuma geçebilmesine de işaret etmektedir; ancak Bilefsky (2008) Arnavutluk’ta da erkek ve kadın rolleri arasındaki uçurumun azaldığını ve dolayısıyla yeminli bakire geleneğini uygulayan kişilerde bir azalma görüldüğ̈̈nü belirtmektedir. Bu azalma toplumsal söylem içerisinde eril olarak tanımlanmış konuma biyolojik olarak kadın olanların da erişimlerinin artmasıyla açıklanabilir.

Tüm bu söylem ve kültürel yapılar değerlendirildiğinde, erillik ve dişiliğin birer konumlanma olarak kurulduğu; söylemlerdeki değişimlerle beraber ise erkeklerin erilliğindeki ve kadının dişilliğinde azalma olduğu ve bu değişimlerin de klinik tablodaki yapılara, semptomlara ve savunmalara yansıdı̆̆ı söylenebilir. Ancak dilde kadına daha geniş alan açılmış olsa da, kadının fallusa tam olarak sahip olmadığına dair işaretlerin olduğu görülmektedir. Dolayısıyla hangi yapıda olursa olsun, kadının kurulumunda dildeki tam olmama hali göz önünde tutulmalıdır. Ek olarak, kadında obsesyon nevrozundan bahsediliyor olsa da biyolojik bir vurgu içeren dişil bir obsesyon nevrozundan bahsedilememektedir (Strauss, 2014). Fallusun Başka'nın söyleminden anlamını alması, öznenin konumlanışına değişebilme olasılığı vermektedir. Her öznenin kurulumu kendine özgü olacağından, öznelerin klinik bağlamda konumlanışları da tüm bunlar ışı̆̆ında kendilerine özgü olarak değerlendirilmelerine işaret etmektedir. 


\section{Kaynakça}

Atmaca, S. (2017). Lacan'ın özne kurulum yaklaşımına göre obsesyon nevrozu. AYNA Klinik Psikoloji Dergisi, 4(1), 14-25.

Bilefsky, D. (2008). Albanian Custom Fades: Woman as Family Man. The New York Times. Erişim: http://www.nytimes.com/2008/06/25/world/europe/25virgins.html?pagewanted=all? pagewanted $=$ print $\& \_r=2 \&$

Dor, J. (1999). The Clinical Lacan. New York, NY: Other Press.

Durudoğan, H. (2015). Unes Femmes: Kristeva, Psikanaliz ve Kadın, İçinde Z. Direk (Ed.), Cinsiyetli olmak: Sosyal bilimlere feminist bakışlar (ss. 51-66). İstanbul: Yapı Kredi Yayınları.

Evans, D. (2006). An Introductionary Dictionary of Lacanian Psychoanalysis. New York, NY: Routledge.

Fink, B. (1997). A Clinical Introduction to Lacanian Psychoanalysis: Theory and Technique. United States: Harvard University Press.

Fink, B. (2016). Lacan on Love: An Explanation of Lacan's Seminar VII, Transference. Cambridge, UK: Polity Press.

Gherovici, P., \& Webster, J. (2014). Observations from working with female obsessionals. The European Journal of Psychoanalysis, 2. Erişim: http://www.journalpsychoanalysis.eu/observations-from-working-with-femaleobsessionals/\#_ftnref1

Gray, R. (2016). Lecture notes: Freud "aetiology of hysteria”. Erişim adresi: http://courses.washington.edu/freudlit/Hysteria.Notes.html

Homer, S. (2013). Jacques Lacan. (A. Aydın, Çev). Ankara: Phoenix Yayınevi (2005).

Lanchin, M. (2009). Arnavut 'yeminli bakireler'. BBC Turkish. Erişim: http://www.bbc.co.uk/turkish/fooc/story/2009/02/090206_fooc_albania.shtml

Miller, D. (2005). Obsession: A name of the super-ego. Symptom. Erişim: http://www.lacan.com/symptom6_articles/obsession-nameofsuperego.html

Online Etymology Dictionary (2017, Haziran). Obsession. Erişim: http://www.etymonline.com/index.php?allowed_in_frame=0\&search=obsession

Lacan, J. (1999). The Seminar of Jacques Lacan, Book XX: On Feminine Sexuality, The Limits of Love and Knowledge (1972-1973), (J.-A. Miller, Ed., \& B. Fink, Çev.). New York, NY: W. W. Norton \& Company.

Lacan, J. (2004). The Seminar of Jacques Lacan, Book X: Anxiety (1962 -1963), (J.-A. Miller, Ed., \& A. R. Price, Çev.). Cambridge, UK: Polity Press.

Lacan, J. (2006a). Ecrits: The First Complete Edition in English (1966), (Editions du Seuil, Ed., \& B. Fink, Çev.). New York, NY: W. W. Norton \& Company.

Lacan, J. (2006b). The Seminar of Jacques Lacan, Book XVI: From an Other to the other (1968-1969),

(C. Gallagher, Çev.). Erişim: http://www.lacaninireland.com/web/translations/seminars/

Soler, C. (1996). Hysteria and Obsession. İçinde R. Feldstein, B. Fink, \& M. Jaanus (Ed.), Reading seminars I and II: Lacan's return to Freud (248-282). New York, NY: State University of New York Press.

Soler, C. (2006). What Lacan Said about Women: A Psychoanalytic Study. New York, NY: Other Press.

Strauss, M. (2014). On female obsessional neurosis. The European Journal of Psychoanalysis, 2.

Erişim: http://www.journal-psychoanalysis.eu/on-the-female-obsessional-neurosis/

Verhaeghe, P. (2008). On Being Normal and Other Disorders: A manual for Clinical Psychodiagnostics. London, UK: Karnac Books. 